\title{
Coatings or impregnations to adequately treat and protect different substrates: toolbox treatments to obtain optimal results in singular buildings
}

\author{
N. García-Pascua ${ }^{1}$, L. Granizo ${ }^{2}$, M. Donadio ${ }^{3}$, H. Baenziger ${ }^{3}$, \\ A. González-Lucas ${ }^{2}$, F. González ${ }^{4}$, M. J. Rubio ${ }^{5} \&$ O. Videra ${ }^{2}$ \\ ${ }^{I}$ Kalam, Spain \\ ${ }^{2}$ Sika, S.A.U., Spain \\ ${ }^{3}$ Sika Services, Switzerland \\ ${ }^{4}$ Betazul, Spain \\ ${ }^{5}$ Polytechnic Madrid University, Spain
}

\begin{abstract}
Normally, hydrophobic treatments and coatings are selectively chosen to repair or protect different substrates depending on the climatic conditions, colour, change of initial aspect of the substrate, etc. The combination of these two different treatments in the same repair work is not normally considered. Recent investigations in different dispersion and impregnations technologies used and a combination of both in different products have been determined to work in synergy to give better results and permit the specific design of the work in each case according to the needs of a particular building or structure. This synergy between impregnations/patinas gave an optimal result in some singular buildings in Madrid. The concept is a toolbox of waterproofing/repair solutions to specifically design the best system on site, after laboratory screening tests.

Keywords: impregnation, dispersion coating, hybrid, synergy.
\end{abstract}

\section{Introduction}

Damage to various kinds of substrates always involves water. Water acts as a vehicle for transporting aggressive substances, such as chloride ions which are present in the water as it is drawn into the concrete by capillary action. Water 
also serves as a reaction medium and a reagent in destructive chemical processes, foremost among these being the corrosion of the reinforcing steel. Corrosion leads to the deterioration of overlying stone. One of the most efficient ways to protect stone and other substrates is to prevent it from absorbing water in the first place [1].

Hydrophobic Impregnation is a proven protection technology that prevents water ingress into structures thus decreasing the likelihood of degradation due to aggressive influences. This technique can be used for both new and existing structures [2].

Depending on the specific situation to repair/protect, maybe some systems must be considered to be used including, waterproofing/ repair mortars and different finishing as different patinas or renders with colors integrated with the original substrate to repair [3]. Sometimes, these systems have to include the required impregnation or must be hydrophobic themselves and must be combined. This solution is more diverse and avoids the limitations of using only one product [4]. Toolbox concept appears, choosing available renders, water repellent and finishings, once they are screened by laboratory tests on the substrate.

These systems can be adapted easier to the required solution needed; it can be that the substrate has to "breathe" rather than to be isolated from the environment [5]. Sometimes it needs complete waterproofing and some others, just to reduce water absorption. Also, from the point of view of aesthetics, sometimes patinas are more adequate to the original aspect and the protection to the external aggressions is more effective [6].

\subsection{Experimental and results}

Two sets of different testing were carried out to compare the results of a single hydrophobic treatment and the application of a complete system in the same substrate. Laboratory tests were the screening phase to the real application of the selected treatment.

The results of these tests provided the most adequate treatment for different singular buildings in different substrates around the Madrid area.

\section{Target}

Collection of data for the selection of the best waterproofing impregnation considering the substrate to be treated, Villamayor sandstone, Salamanca, of coarse and fine grain [7].

\subsection{Tests to be carried out}

The tests involve the study of a series of commercial waterproofing impregnations in base to the following tests [8]:

1. - Product layout.

2. - Colorimetric variation of the substrate after the application. 
3. - Hydric behavior: study of water absorption (capillary and immersion) and water evaporation capacity.

4. - Tests to define the system structure: open porosity to water, apparent density, real density and total.

5. - Accelerated aging of the system.

6. - Hydric study after ageing.

7. - Other treatments needed [9].

A comparative study among 7 water repellent products is carried out. General characteristics of these products are given in table 1:

Table 1: General characteristics.

\begin{tabular}{|c|c|c|c|}
\hline PRODUCT & Chemical Composition & Solvent & Concent. in appl. \\
\hline (H1) & Alquilsiloxanes & White spirit & Pure \\
\hline (H2) & Alquilsiloxanes & White spirit & Pure \\
\hline (H3) & Alquilsiloxanes & White spirit & Pure \\
\hline (H4) & Alquilsiloxanes & White spirit & Pure \\
\hline (H5) & Alquilsiloxanes & White spirit & Pure \\
\hline (H6) & Alquilsiloxanes & White spirit & Pure \\
\hline (H7) & Alquilsiloxanes & White spirit, Xileno, Toluene & Pure \\
\hline
\end{tabular}

The products could be applied on the different substrates to study with a brush until the substrate is saturated. In our case, one of the substrates selected was special sandstone with spread use in some areas in Spain in historical and singular buildings [10].

Tests on natural stones:

All the products were applied with a brush until saturation of the surfaces. The excess of product was eliminated cleaning with the corresponding solvent.

Table 2: $\quad$ Layout of the products.

\begin{tabular}{|c|c|c|}
\hline Treatment & Mean layout $\left(1 / \mathrm{m}^{2}\right)$ & Technical layout $\left(1 / \mathrm{m}^{2}\right)$ \\
\hline $\mathbf{( H 1 )}$ & 0.586 & 0.500 \\
\hline $\mathbf{( H 2})$ & 0.506 & $0.333-0.500$ \\
\hline $\mathbf{H 3})$ & 0.432 & $0.250-0.333$ \\
\hline $\mathbf{( H 4 )}$ & 0.436 & ----- \\
\hline $\mathbf{H 5})$ & 0.566 & $0.50-0.150$ \\
\hline $\mathbf{H 6})$ & 0.364 & ---- \\
\hline $\mathbf{( H 7 )}$ & 0.576 & $0.370-0.620$ \\
\hline
\end{tabular}




\subsection{Colorimetric variation of the surface after treatment with the product}

A very important aspect of the water repellent application is the final color of the substrate. Normally, it is required that the susbtrate maintains its original color and gloss. This is the reason why a colorimetric study is carried out. This study consists in the measurement of the color of the specimen before and after the application of the product. Before the application of the water repellent treatment, there is an initial color scanning of 30 colorimetric random measurements on all the specimens used in this study. After that, the application of the different water repellent products is done. After the drying of the products, 30 colorimetric measurements are carried out for each product. Then, colorimetric analysis is done.

Reflectance variation after the water repellent treatment is followed. With the measurement of reflectance $(\mathrm{R})$, whiteness degree is measured (values close to $100 \%$ ) or darkness (values close to $0 \%$ ). The specimen without treatment has a value of approx. $20 \%$ (dark tones). Variation of each treatment is shown in the following table.

Table 3: $\quad$ Influence on reflectance.

\begin{tabular}{|c|c|}
\hline Water repellent & Influence on reflectance \\
\hline (H1) & R decreases 5\%, darkener \\
\hline (H2) & R is maintained \\
\hline (H3) & R decreases $2 \%$, darkener \\
\hline (H4) & R decreases 4\%, darkener \\
\hline (H5) & R decreases 4\%, darkener \\
\hline (H6) & R is maintained \\
\hline (H7) & R decreases 4\%, darkener \\
\hline
\end{tabular}

Table 4: $\quad$ Colorimetric results.

\begin{tabular}{|c|c|c|}
\hline Water repellent & Parameter $\mathbf{a}^{*}(+\equiv \mathbf{r e d})$ & Parameter $\mathbf{b}^{*}(+\equiv$ yellow $)$ \\
\hline (H1) & Slightly increases & Slightly increases \\
\hline (H2) & same & Same \\
\hline (H3) & Slightly increases & Same \\
\hline (H4) & Slightly increases & Slightly increases \\
\hline (H5) & Slightly increases & Same \\
\hline (H6) & Slightly increases & Slightly increases \\
\hline (H7) & Increases & Increases \\
\hline
\end{tabular}

Colorimetric results indicate that $(\mathrm{H} 2)$ is the product with less chromatic alteration on specimen. 
Hydric behavior: Study of water absorption by capillarity and evaporation test.

In this type of substrate, total immersion is not tested, due to the holes in the specimen.

- Capillarity test: capillarity absorption is the amount of water absorbed by a Stone surface, initially dried, in contact with a water surface during a determined period of time. In the methodology described in Standard Document 11/85, samples are immersed in a way that the base of the simple is immersed $2 \mathrm{~mm}$ high and specimens are weighed at given times. Capillarity coefficient $(\mathrm{Cc})$ is a function of the water mass absorbed (M) by surface unit (S) and the square root of time $(\mathrm{t})$, it is given in $\left(\mathrm{g} / \mathrm{cm}^{2} \mathrm{~s}^{0.5}\right)$.

$$
C_{c}=\frac{M}{S t^{1 / 2}}
$$

Capillary absorption curves are given as $\%$ of absorbed water as a function of time. The water height is maintained, adding water when needed.

Capillarity analysis is first carried out over untreated specimen specimens to obtain saturation coefficient of the specimen to later compare after the treatment with the water repellent product.

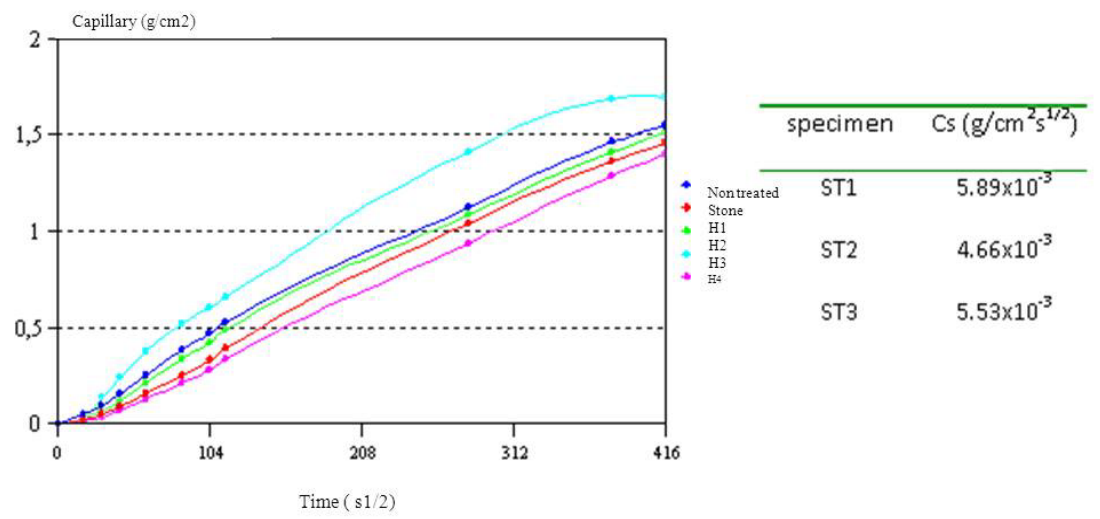

Figure 1: First capillarity analysis.

All the specimens have a similar behaviour, with a saturation coefficient of around $5.36 \times 10^{-3} \mathrm{~g} / \mathrm{cm}^{2} \mathrm{~s}^{1 / 2}$. The water absorption rate of the specimen is continuous and the saturation time is occurring at 48 hours of test.

The following results show the behaviour of the treated specimens compared to the untreated ones.

Water repellent treatment considerably reduced capillarity water absorption. (H2) is giving worst water repellent properties at 48 hours removing the curve of the untreated specimen, the differences among the products can be observed. 


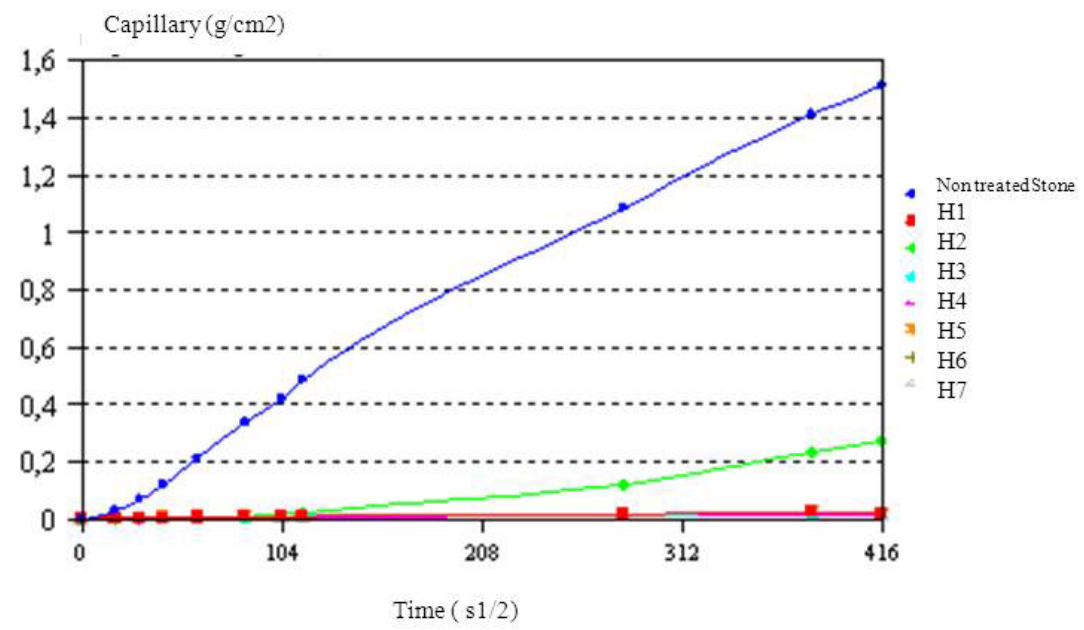

Figure 2: Behaviour of the treated specimens.

The graph of figure 3 shows that all the products except $(\mathrm{H} 2)$ maintain the absorption rate. From the graph, capillarity saturation coefficients can be calculated:

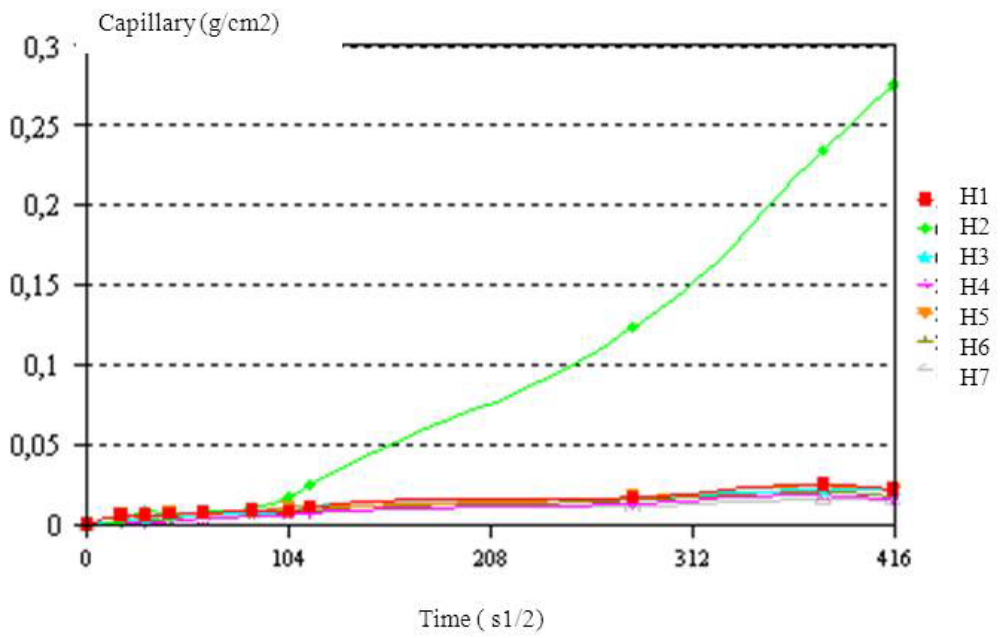

Figure 3: Absorption rate.

After 48 hours of testing, the specimen is protected with Para film in all the surfaces except the one that have been in contact with water and they are weighed at regular intervals of time until constant weight, following then the water absorbed through waterproofed surface. The test is carried out at room conditions. 
Table 5: Weight.

\begin{tabular}{|c|c|c|}
\hline Product & $\mathbf{C}_{\mathrm{c} 1}\left(\mathrm{~g} \mathrm{~cm} / \mathbf{s}^{(1 / 2)}\right)$ & $\mathbf{C}_{\mathrm{c} 2}\left(\mathrm{~g} \mathrm{~cm} / \mathbf{s}^{(1 / 2)}\right)$ \\
\hline (H1) & $0.50 \times 10^{-4}$ & $5.80 \times 10^{-4}$ \\
\hline (H2) & $2.20 \times 10^{-4}$ & \\
\hline (H3) & $0.70 \times 10^{-4}$ & \\
\hline (H4) & $0.40 \times 10^{-4}$ & \\
\hline (H5) & $0.80 \times 10^{-4}$ & \\
\hline (H6) & $0.40 \times 10^{-4}$ & \\
\hline (H7) & $0.40 \times 10^{-4}$ & \\
\hline
\end{tabular}

The curves of water desorption through evaporation of the untreated specimen is shown in fig. 4 :

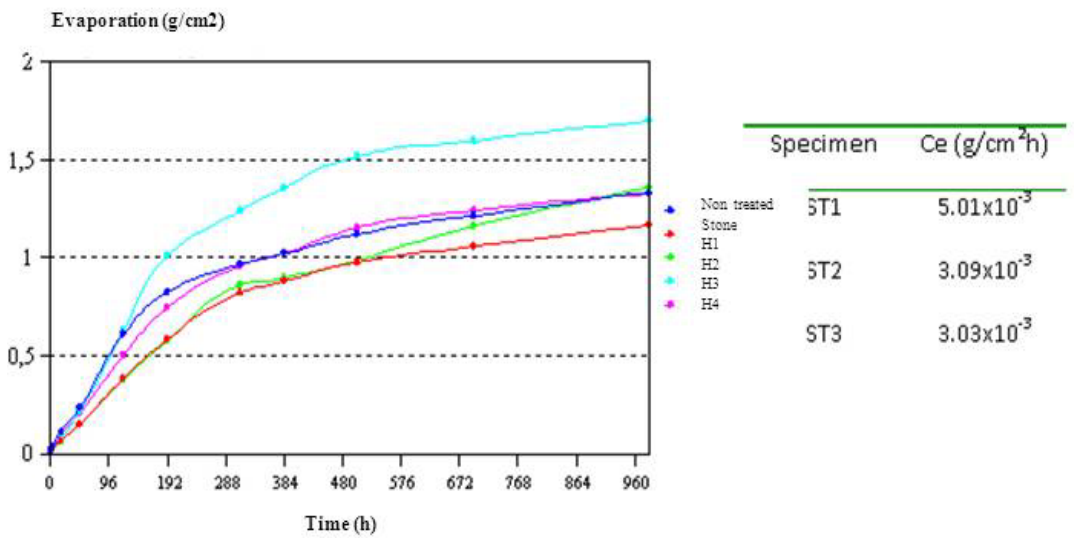

Figure 4: Water desorption.

The evaporation of the untreated specimens is similar with an evaporation coefficient of $4.08 \times 10^{-3} \mathrm{~g} / \mathrm{cm}^{2} \mathrm{~h}$.

Then, the behaviour of the treated specimens during the evaporation process is shown, compared to the behaviour of the untreated specimens (fig. 5). 


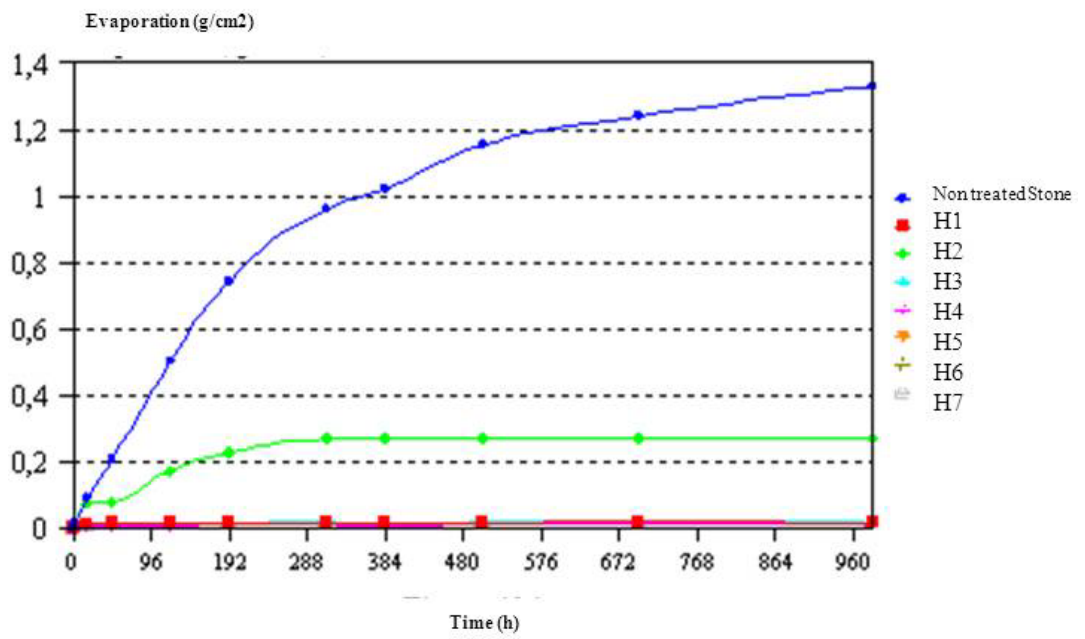

Figure 5: Evaporation process.

As can be observed, treated specimens evaporate slower the water absorbed during capillarity test (fig. 6).

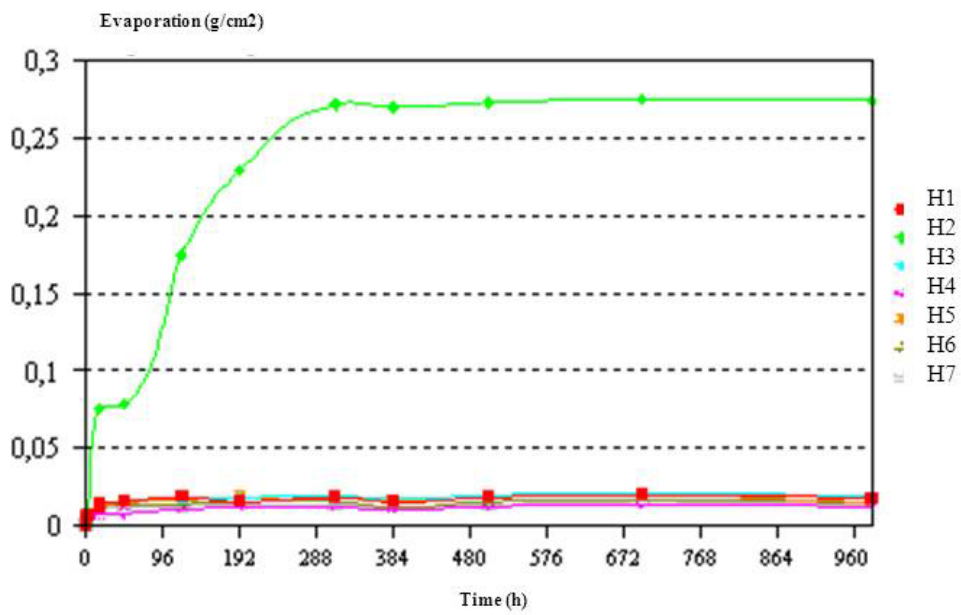

Figure 6: Evaporate slower during capillarity test.

It can be seen that all the products except (H2), have a similar behaviour. Eliminating this curve, the characteristic behaviour of the rest of the products can be observed (fig. 7). 


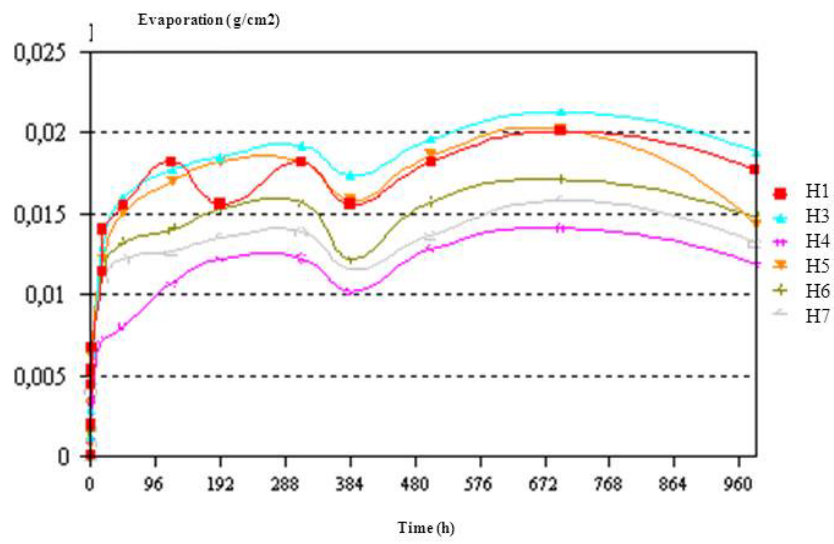

Figure 7: Characteristic behaviour.

The products with the same capillarity water absorption coefficient $((\mathrm{H} 4)$, (H6) and (H7)) present different evaporation coefficients.

Table 6: Evaporation coefficients.

\begin{tabular}{|c|c|}
\hline Product & $\mathbf{C}_{\mathrm{e}}(\mathrm{g} \mathrm{cm} / \mathbf{h})$ \\
\hline $\mathbf{( H 1 )}$ & $0.80 \times 10^{-3}$ \\
\hline $\mathbf{( H 2 )}$ & $1.52 \times 10^{-3}$ \\
\hline $\mathbf{( H 3 )}$ & $0.79 \times 10^{-3}$ \\
\hline $\mathbf{( H 4 )}$ & $0.46 \times 10^{-3}$ \\
\hline (H5) & $1.01 \times 10^{-3}$ \\
\hline (H6) & $0.70 \times 10^{-3}$ \\
\hline (H7) & $0.79 \times 10^{-3}$ \\
\hline
\end{tabular}

Porosity accessible to water is defined as the ratio between the volume of the pores accessible to water and the apparent volume of the sample. This represents the volume of the pores connected as a percentage of the total volume of the sample.

Method described by RILEM recommendations is followed. Samples are dried until constant weight (M1), at temperature between $40-70^{\circ} \mathrm{C}$.

Samples are in a vacuum vessel connected to vacuum during 24 hours. Then water is introduced into the vessel to cover the samples during 24 hours. Then, without vacuum, another 24 hours are waited. Saturated samples are then weight in water (M2) and air (M3).

The value of porosity accessible to water (in \%) is: 


$$
P A=\frac{M_{3}-M_{1}}{M_{3}-M_{2}} \times 100
$$

M1, is the mass of the dry specimen; M2, the mass of the specimen saturated in vacuum, weighed immersed (hydrostatic weight of the specimen saturated in vacuum) and, M3, mass of the specimen saturated in vacuum weighed at atmospheric pressure.

Total porosity is the volume of empty spaces, communicated or not, in the material, in \%. If all the pores will be connected and connected outside, total porosity and open porosity would be the same.

$$
P T=\frac{\rho r-\rho a}{\rho r} \times 100
$$

where $\rho_{\mathrm{r}}$, is the real density in $\mathrm{g} / \mathrm{cm} 3$ and, $\rho_{\mathrm{a}}$, apparent density.

Apparent density is the ratio between the mass and the apparent volume determined by the external surface of the sample (in $\mathrm{g} / \mathrm{cm} 3$.)

$$
\rho_{a}=\frac{M_{1}}{M_{3}-M_{2}} 5
$$

Real density is the ratio between mass and impermeable volume of the simple. Where impermeable volume is the volume of the pores accessible to water, this is, the volume of the solid sample plus the volume of the pores non accessible to water (in) $\mathrm{g} / \mathrm{cm} 3$.

$$
\rho_{r}=\frac{M_{1}}{M_{1}-M_{2}}
$$

Values of the physical properties are shown for the different treatments.

Accelerated ageing of the system specimen, water repellent treatment, and the loss of efficiency of the treatments can be followed with these tests. The aspect of the system will be followed over successive cycles and, after 30 cycles, water absorption tests should be done to know the influence of the aging.

- Cycles of freeze-thaw. The samples, once dried until constant weight, were subject to $-5^{\circ} \mathrm{C}$ during 4 hours. Then, they are immersed in water at room temperature during 20 hours. Weight differences are measured to follow the evolution and efficiency of the treatments.

The process of aging was stopped because samples were damaged. The most damaged stones were the ones with higher water absorption

As a conclusion, it can be said that the detailed study of different commercial products result in very different behaviour of hydrorepelent properties, even for the same chemical base. Different concentrations of active material can be involved and a detailed study of all the aspects of the treatment has to be carried out when the application involves singular buildings. 
Table 7: $\quad$ Physical properties.

\begin{tabular}{|c|c|c|c|}
\hline product & $\begin{array}{c}\text { Porosity accessible } \\
\text { to water, PA (\%) }\end{array}$ & $\begin{array}{c}\text { Apparent density, } \\
\rho_{\mathbf{a}}\left(\mathbf{g} / \mathbf{c m}^{\mathbf{3}}\right)\end{array}$ & $\begin{array}{c}\text { Real density, } \\
\rho_{\mathbf{r}}\left(\mathbf{g} / \mathbf{c m}^{\mathbf{3}}\right)\end{array}$ \\
\hline Non treated & 21.60 & 2.064 & 2.632 \\
\hline (H1) & 21.44 & 2.067 & 2.631 \\
\hline (H2) & 21.59 & 2.066 & 2.635 \\
\hline (H3) & 22.35 & 2.062 & 2.656 \\
\hline (H4) & 20.51 & 2.061 & 2.593 \\
\hline (H5) & 20.21 & 2.067 & 2.590 \\
\hline$(\mathbf{H 6})$ & 21.32 & 2.093 & 2.660 \\
\hline$(\mathbf{H 7})$ & 20.06 & 2.069 & 2.588 \\
\hline
\end{tabular}

Table 8: Weight.

\begin{tabular}{|c|c|c|c|c|c|c|}
\hline Sample & $\begin{array}{l}\text { Initial } \\
\text { weight } \\
\text { Po }(g)\end{array}$ & $\begin{array}{c}\text { Weight } \\
\text { after } 5 \\
\text { cycles }(\mathrm{g})\end{array}$ & $\begin{array}{c}\text { Weight after } \\
10 \mathrm{c}(\mathrm{g})\end{array}$ & $\begin{array}{l}\text { Weight after } \\
20 \mathrm{c}(\mathrm{g})\end{array}$ & $\begin{array}{c}\text { Dry } \\
\text { weight } \\
\text { end }(g)\end{array}$ & $\begin{array}{l}\text { Weight } \\
\text { diff. (g) }\end{array}$ \\
\hline $\begin{array}{c}\text { Non } \\
\text { treated1 }\end{array}$ & 183.56 & 202.91 & 203.85 & 202.91 & 176.15 & -7.41 \\
\hline $\begin{array}{c}\text { Non } \\
\text { treated2 }\end{array}$ & 176.30 & 195.44 & 196.32 & 191.70 & 165.42 & -10.88 \\
\hline (H1) & 171.99 & 178.44 & 183.10 & 190.65 & 169.80 & -2.19 \\
\hline (H6) & 176.84 & 195.70 & 198.32 & 197.12 & 167.39 & -9.45 \\
\hline (H7) & 178.39 & 188.45 & 192.25 & 198.97 & 175.79 & -2.60 \\
\hline (H4) & 178.46 & 193.23 & 196.25 & 193.45 & 168.01 & -10.45 \\
\hline (H3) & 171.90 & 183.96 & 188.08 & 180.21 & 157.60 & -14.30 \\
\hline (H5) & 176.78 & 194.54 & 198.30 & 200.75 & 171.69 & -5.09 \\
\hline (H2) & 176.27 & 196.17 & 199.58 & 196.36 & 167.46 & -8.81 \\
\hline
\end{tabular}


For special areas of the building already treated in former restorations, special renders and coatings were proposed to be used. Some screening tests in the laboratory and on site were carried out to test the adhesion of the renders and coatings on the old substrates (mainly gypsum and old coatings) to assure the protection and the durability of the treatments. These areas have no sandstone in the moment of the repair. Example:

Lime based render

This mortar was applied on different substrates (render, gypsum and concrete), with different traditional finishes. After seven days from the application, the adhesion of the mortar on the different susbtrates is studied as well as the general aspect of the mortar as cracks or blistering.

Table 9: $\quad$ Render.

\begin{tabular}{|c|c|}
\hline Finishing & Adherence $(\mathrm{MPa})$ \\
\hline Not textured & 8,3 \\
\hline Trowel & 1,9 \\
\hline Sponge & 1,4 \\
\hline
\end{tabular}

Table 10: Gypsum.

\begin{tabular}{|c|c|}
\hline Finishing & Adherence $(\mathrm{MPa})$ \\
\hline Not textured & 7,0 \\
\hline Trowel & 11,0 \\
\hline Sponge & 6,4 \\
\hline
\end{tabular}

\subsection{Water based coatings and silicate patina}

This system is applied also on different substrates with and without primer

Table 11: $\quad$ Render.

\begin{tabular}{|c|c|}
\hline IPrimer & Adherence (Kgf) \\
\hline Yes & $<0.05$ \\
\hline No & $<0.05$ \\
\hline
\end{tabular}


Table 12: Gypsum.

\begin{tabular}{|c|c|}
\hline primer & Adherence $(\mathrm{MPa})$ \\
\hline Yes & 2,7 \\
\hline No & 1,8 \\
\hline
\end{tabular}

Also, further complete studies were carried out on site to defined treatments according to the adhesion differences depending on the finishes and according to the "old" renders and coatings found.

The selection of the best treatment was designed specifically for each case considering this adhesion study and the observation of field trials in the reality.

The adhesion of the system is quite high in most of the substrates studied. When the substrate is very old and damaged, special considerations have to be taken into account. Depending on the type of finishing, also adhesion differences are found that have to be tested on site to avoid cracks or defects. Further studies this adhesion study should be done ideally when singular buildings have to be treated to avoid wrong selection of treatments.

\section{Conclusions}

1. When singular buildings are going to be treated with waterproofing systems, detailed study on the different aspects of the application and products should be carried out.

2. Screening tests are carried out in the laboratory with real substrates to really defined behavior with the proposed treatments. These tests should be carefully compared after ageing of the samples.

3. Detailed waterproofing products selection has to be tested on site to confirm previous results.

4. Design of specific systems for each substrate and each characteristic building part, has to be done, considering a Toolbox of water repellent products, available renders and compatible coatings with the elements to be treated. The success of the treatments depends on the handling of this toolbox, complementing laboratory tests with the field trials in the real building.

\section{References}

[1] Miller, M., History of cementitious and polymer technology, and their unison, Rapra Technology Limited, 2005.

[2] Ohama, Y., Handbook of polymer-modified concrete and mortars, William Andrew; 1 edition, ISBN 0-8155-1358-5, 1996. 
[3] Ohama, Y., Polymer-based admixtures, cement and concrete composites, 1998.

[4] Schulze, J., Influence of water-cement ratio and cement content on the properties of polymer-modified mortars, cement and concrete research, Elsevier, 1999.

[5] Ramachandran,V.S., Concrete admixtures properties, science, and technology, Noyes Pubns, second edition, 1984.

[6] Kuhlmann, L.A., Walters, D.G., Polymer modified hydraulic-cement mixtures, Astm Intl, 1993.

[7] Lamod, J., Pielert, H., Significance of tests and properties of concrete and concrete- making materials, Astm Intl, 2006.

[8] Polymer Chemist http://faculty.uscupstate.edu/llever/Polymer\%20 Resources/Mechanical.htm

[9] Sánchez, J.A., Historia, caracterización y restauración de morteros, Universidad de Sevilla. secretariado de publicaciones, 2003.

[10] Pellicer, F., Potential uses for polymer modified repointing mortars, Proceedings of 9th Canadian Masonry Symposium, University of New Brunswick, June 2001. 